\title{
The soul of the business!
}

\author{
JOSÉ ANTÔNIO BADDINI MARTINEZ
}

As the saying goes, "Secrecy is the soul of business!"

Following this philosophy and the example of the majority of international journals, the Jornal Brasileiro de Pneumologia (Brazilian Journal of Pulmonology) evaluates the articles submitted for publication through a peer review process in which the anonymity of the authors, as well as that of the reviewers, is safeguarded. Although this method has been a target of criticism, we believe that the majority of people working in the field of scientific editing still prefer this method of evaluation..$^{(1-3)}$ The aim of using such a system is to ensure that rulings will be made in a way that is as unbiased as possible, uninfluenced by ties of friendship, personal interests or potential conflicts of interest. Certainly, this methodology also prevents embarrassment of the parties involved.

In this issue of the Brazilian Journal of Pulmonology, we published a list of the names of the reviewers of the articles processed in 2005. Included in this list are those who were involved in the review of the manuscripts published in all six issues of Volume 31 , as well as those who analyzed articles that were definitively rejected in this period. In the future, the names of the reviewers of in-press articles and of articles that are still under review will also be listed.

Since links to specific articles were not revealed, publishing these names does not constitute a breach of reviewer anonymity. Instead, it is only in recognition of the work carried out by key members of the team participating in the workings of the journal. Within the structure of any scientific journal, and that of the Brazilian Journal of Pulmonology in particular, the reviewers play one of the most important roles. As Dr. Geraldo Lorenzi said, "Without reviewers, there is no journal; they embody its spirit." ${ }^{(4)}$ The peer review process exists because it is very difficult for one group of authors to see every nuance of a certain issue clearly and identify all of the mistakes and omissions that might exist in any given article. When an article is evaluated by individuals recognized as having scientific capacity and knowledge in the area, there is a greater likelihood that the quality of that article will be enhanced through the incorporation of recommendations and suggestions made by the reviewers. ${ }^{(2)}$ In addition, the review process makes it possible to maintain the level of quality of the journal and to adhere to editorial policy.

The tasks carried out by journal reviewers are complex. It has even been recommended that proficiency courses be created that are specific to this function. ${ }^{(5)}$ The reviewers of articles submitted to our journal are typically chosen from among the members of the Editorial Board, although others are occasionally invited to review a submission. The Editor-in-Chief and the Associate Editors, each within their own field, nominate professionals recognized as knowledgeable about the theme in question, and the secretary of the journal inquires of these professionals regarding their availability to review the article in question. After having accepted the task, the reviewer receives the article, minus any information that might identify the authors or the institution of origin, via e-mail.

The reviewers receive no remuneration, and reviewing an article takes time away from their professional responsibilities and, more importantly, from their leisure time. Frequently, a review demands that a supplementary bibliography be consulted and that additional articles be actively sought. The complexity of methodological questions and statistical tests can also require that other colleagues who are specialized in these fields be consulted. In addition, the entire process must be completed in a timely fashion, ideally within a month for first submissions, and within two weeks for additional submissions. Although it is desirable that the final decision about a manuscript occur soon after the second submission, some articles are accepted only upon their fourth or fifth submission. Naturally, all of these steps demand time, concentration and hard work. Over and above 
all that, these tasks are carried out silently, in secrecy, counting only on the recognition by the members of the Editorial Board involved in that specific review.

The reviewers of the Brazilian Journal of Pulmonology are altruistic individuals who voluntarily devote their time and efforts to the growth of our Journal and of the Sociedade Brasileira de Pneumologia e Tisiologia (Brazilian Society of Pulmonology and Phthisiology). Their high-quality work has contributed greatly to improving the material published by our journal. Pertinent suggestions routinely enrich the analysis of the results, make data presentation clearer and make the content of the discussions more sophisticated. The increased rapidity with which articles have been evaluated of late has only been possible because most of the reviewers meet the deadlines set.

At the end of another year, we would like to thank all of the reviewers who, with good will, impartiality and boldness, have worked toward the advancement of the Journal. It is imperative to know that we can rely on their continued dedication and conscientiousness in order to reach new heights in the near future.

Yes, the popular wisdom is right:

The work carried out in secrecy by the reviewers is the soul of the Brazilian Journal of Pulmonology!

JOSÉ ANTÔNIO BADDINI MARTINEZ

Editor-in-Chief of the Brazilian Journal of Pulmonology

\section{REFERENCES}

1. Justice AC, Cho MK, Winker MA, Berlin JA, Rennie D, and the PEER investigators. Does masking author identity improve peer review quality? A randomized controlled trial. JAMA. 1998;280(3):240-2.

2. Laine C, Mulrow C. Peer review: integral to science and indispensable to Annals. Ann Intern Med. 2003;139(12): 1038-40.

3. Roberts JC, Fletcher RH, Fletcher SW. Effects of peer review and editing on the readability of articles published in Annals of Internal Medicine. JAMA. 1994;272(2):119-21.

4. Lorenzi G. O espírito do Jornal de Pneumologia. J Pneumol. 2003;29(6):335.

5. Schroter S, Black N, Carpenter J, Godlee F, Smith R. Effects of training on quality of peer review: randomized controlled trial. BMJ. 2004;328(7441):673-5. 